\section{Research Square}

\title{
A Turbulence Scaling Factor that converts laminar solutions to turbulent solutions
}

\author{
Huseyin Onur ( $\nabla$ hsonur@yahoo.com ) \\ Işık University
}

\section{Article}

Keywords:

Posted Date: October 9th, 2020

DOl: https://doi.org/10.21203/rs.3.rs-86923/v1

License: (a) (i) This work is licensed under a Creative Commons Attribution 4.0 International License. Read Full License 


\section{A Turbulence Scaling Factor that converts laminar solutions to turbulent solutions}

The pictures, illustrations and descriptions from flow visualisation studies show that one signature of turbulence is the fragmentation of the fluid. This fragmentation or internal roughness of the turbulent fluid must be the reason for the high friction forces ; one may assume that the main difference between laminar and turbulent flows is their internal friction surfaces which are Euclidean surfaces for laminar flows and fractal surfaces for turbulent flows .

Let us denote the dimention of a fractal surface embedded in $3 \mathrm{D}$ space as $\mathrm{D}_{3}$; If a plane intersects this fractal surface we have the dimention $D_{2}$ and $D_{3}=D_{2}+1$ relates $D_{2}$ to $D_{3}$. For very high Reynolds numbers turbulent fractal surface is space filling i.e. as $\operatorname{Re} \rightarrow \infty$ $\mathrm{D}_{3} \approx 3$.

I take a cube of volume $\mathrm{L}^{3}$ in the fluid and suppose that there are $\mathrm{N}$ eddies in it then $\mathrm{N}=\mathrm{L}^{3} / \eta^{3}$ where L is the characteristic length of flow geometry and $\eta$ is the largest characteristic eddy length. It is an experimentally observed fact that increasing Re number makes $\eta$ smaller so $\mathrm{N}$ increases with increasing Re number. A simple plausible way to compare laminar and turbulent friction surface areas is to look at the ratio of total external areas of small cubes to the parent cube's area;

$$
\Gamma=\mathrm{N} 6 \eta^{2} / 6 \mathrm{~L}^{2}=\mathrm{L} / \eta=N^{1 / 3}
$$

I call $\Gamma$ fractional increase in friction area which is a scaling factor of turbulence and related to turbulence caused fragmentation of fluid. If what is said is correct then $\mathrm{L} / \eta$ is also the ratio of turbulent stresses to laminar stresses for a case for which both laminar and turbulent flows may occur, i.e;

$$
\Gamma=\mathrm{L} / \eta=\tau_{w}^{t} / \tau_{w}^{l}
$$

I have selected shear stresses at wall for turbulent and laminar flows as $\tau_{w}^{t}$ and $\tau_{w}^{l}$ since there are large number of reliable experiments for different flow geometries. I will use pipe flow data in obtaining $\Gamma$ as it is one of the most intensively studied fluid 
dynamics problem. Traditionally friction factor $\lambda, \lambda=\Delta p /\left(0.5 \rho \mathrm{u}^{2} \mathrm{D} / 1\right)$ is plotted against Re number where $\Delta \mathrm{p}$ is the pressure drop along the distance 1 through pipe , $\mathrm{u}$ is the mean velocity, $\rho$ is the density of fluid and $D$ is the diameter of pipe. $\operatorname{Re}=u D / v, v$ being the kinematic viscosity. Some researchers used fanning friction factor $C_{f}=\tau_{w} /\left(0.5 \rho u^{2}\right), \tau_{w}$ being the shear stress on the pipe wall. It is easy to see that $C_{f}=\lambda / 4$.

There are two famous graphs : Nikuradse ${ }^{(1)}$ and Moody ${ }^{(2)}$ diagrams. On these charts one can see three distinct regimes of turbulent flow with regard to friction factor; smooth flow regime where friction factor depends only on Re number , transitionally rough regime where both Re number and relative roughness of wall are important and a fully rough regime where friction factor depends only on relative roughness of wall , k / D, k is the roughness thickness penetrating into fluid.

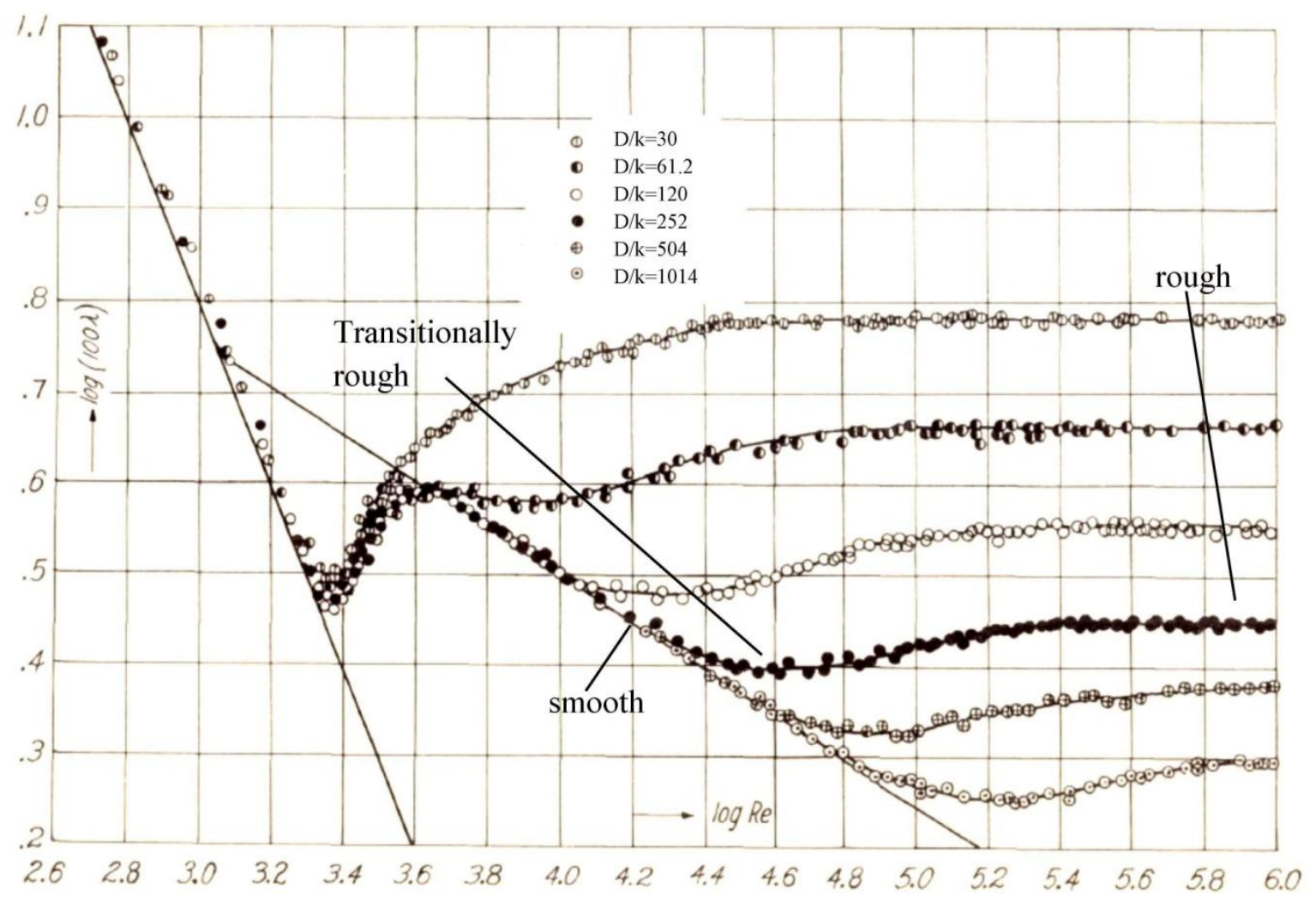

Figure 1. Nikuradse diagram

Fig.1 illustrates these flow regimes on Nikuradse's chart. Power law and logaritmic law for velocity profiles are the two main assumptions in establishing a functional link between 
friction factor and Re number. Both approaches are mostly due to Prandtl . A good summary on these can be found in ref.(3) .

$1-$ Smooth flow

Fractal nature and self similarity of turbulence imposes the use of a power law form for the friction factor - Re number dependency and it must also allow variable coefficients , i.e.

$$
\mathrm{C}_{\mathrm{f}}=\mathrm{A}(\mathrm{Re}) R e^{B(R e)}
$$

I used available experimental data ${ }^{(1),(4),(5)}$ in obtaining the following equation for smooth pipe flow skin friction coefficient $C_{f}^{\eta}$.Details are given in Supplementary Information Section A .

$$
\begin{gathered}
C_{f}^{\eta}=0.84 R e^{-1 / 3} \operatorname{Re}^{-0.206 \operatorname{erfc}\left(\frac{\ln R e}{\ln R e c}-1\right)} \\
\ln \operatorname{Rec}=8.105+0.3971 \operatorname{erf}(\ln \operatorname{Re} / 8.105-1)
\end{gathered}
$$

Where Rec is the critical Re number, erf and erfc are the standart error function and complementary error function respectively. This fit is not designed to be the best fit of data and performance of it will be seen by the application of the turbulent viscosity based on it .

Exact analytical solution for laminar pipe flow gives the following skin friction formula ;

$$
C_{f}^{l}=16 / \operatorname{Re}
$$

Using eqn.(4) and eqn.(5) in eqn.(2) gives $\Gamma$ as ;

$$
\Gamma=\tau_{w}^{t} / \tau_{w}^{l}=C_{f}^{\eta} / C_{f}^{l}=0.0525 R e^{2 / 3} R e^{-0.206 \operatorname{erfc}\left(\frac{\ln R e}{\ln R e c}-1\right)}
$$

Now we can define a turbulent viscosity using eqn.(6)

$$
\tau_{w}^{t}=\Gamma \tau_{w}^{l}=\Gamma \mu(\partial u / \partial r)_{\mathrm{w}}=\mu_{t}(\partial u / \partial r)_{\mathrm{w}}
$$

i.e. $\quad \mu_{\mathrm{t}}=\Gamma \mu$ and $\Gamma$ is the scaling factor for viscosity .

$$
\Gamma=\mu_{\mathrm{t}} / \mu=v_{\mathrm{t}} / \nu=0.0525 \operatorname{Re}^{2 / 3} \operatorname{Re}^{-0.206 \operatorname{erfc}\left(\frac{\ln R e}{\ln R e c}-1\right)}
$$

It is worth noting that equation (6) also gives the dimention of turbulence since $\mathrm{N}^{1 / 3}=\mathrm{L} / \eta$ is defined as a stress ratio with eqn.(2) and stresses act on planes which intersects with turbulent fractal surface hence $\mathrm{N}=\mathrm{K} R e^{D}, \mathrm{D}=\mathrm{D}_{2}$ is the appropriate form for $\mathrm{N}$. 


$$
\begin{aligned}
\Gamma=\mathrm{L} / & \eta=N^{1 / 3}=K^{1 / 3} R^{D^{/ 3}}=0.0525 \operatorname{Re}^{2 / 3} \operatorname{Re}^{-0.206 \operatorname{erfc}\left(\frac{\ln R e}{\ln R e c}-1\right)} \text { since } \mathrm{D}=\mathrm{D}_{2} \\
\mathrm{D}_{2} & =2-0.618 \mathrm{erfc}(\ln \operatorname{Re} / \ln \operatorname{Rec}-1) \quad \text { and } \\
\mathrm{D}_{3} & =3-0.618 \mathrm{erfc}(\ln \operatorname{Re} / \operatorname{lnRec}-1)
\end{aligned}
$$

At critical $\operatorname{Re}$ number i.e. when $\operatorname{Re}=\operatorname{Rec}$, eqn.(8) gives $\mathrm{D}_{3}=2.382$ and for $\operatorname{Re}>3 \operatorname{Rec}$ $\mathrm{D}_{3} \cong 3$. Ref.(6) gives fractal dimentions of turbulent/ non-turbulent interface for boundary layer, axisymmetric jet, plane wake and mixinglayer as ; 2.38, 2.33, 2.37 and 2.40 which are close to 2.382 .

In order to obtain turbulent skin friction coefficients eqn.(7) will be used in place of (laminar) viscosity for cases for which there are solutions for laminar flows and calculated turbulent friction coefficients will be compared with available experimental data.

A - Fully developed flow in rectangular channels

There is an analytical solution for fully developed laminar velocity profile in rectangular ducts $^{(3)}$. Friction factor is given in terms of aspect ratio and Reynolds number which is based on hydraulic diameter and mean velocity. Ref.(7) and Ref.(8) give experimental turbulent friction factors for a wide range of Re numbers. An aspect ratio of $a / b=8$ was used in these experiments and results are presented in terms of a mean Re number in which channel width ,b, is used as reference length instead of hydraulic diameter , $D_{h}=4$ Area /Perimeter. For an aspect ratio of 8 following equation for friction coefficient comes from analytical solution ;

$$
\mathrm{C}_{\mathrm{f}}=20.59 / \operatorname{Re}_{\mathrm{h}}=20.59 v /\left(\mathrm{u} \mathrm{D}_{\mathrm{h}}\right)
$$

In order to obtain turbulent friction coefficient $C_{f}^{\eta}$, I replace $v$ with $v_{\mathrm{t}}$ given with eqn.(7)

$$
C_{f}^{\eta}=1.081 R e_{h}^{-1 / 3} R e_{h}^{-0.206 \operatorname{erfc}\left(\frac{\ln R e}{\ln R e c}-1\right)}
$$

Since friction coefficients in ref.(7) and ref.(8) are presented against $\operatorname{Re}_{\mathrm{m}}=\mathrm{u} \mathrm{b} / \mathrm{v}$, $\mathrm{Re}_{\mathrm{h}}$ must be replaced by $\mathrm{Re}_{\mathrm{m}}$ for comparison and $\mathrm{Re}_{\mathrm{h}}=1.778 \mathrm{Re}_{\mathrm{m}}$ must be used in eqn.(10) Hence;

$$
C_{f}^{\eta}=1.081\left(1.778 \operatorname{Re}_{\mathrm{m}}\right)^{-1 / 3}\left(1.778 \mathrm{Re}_{\mathrm{m}}\right)^{-0.206 \mathrm{erfc}(\operatorname{lnRe} / \mathrm{lnRec}-1)}
$$




$$
\operatorname{lnRec}=8.105+1.382 \operatorname{errf}(\operatorname{lnRe} / 8.105-1)
$$

0.3971 is now replaced by 1.382 in eqn.(11a) as Rec changes differenly in channel flow compared with pipe flow. Table (1) compares eqn.(11) with experimental $\mathrm{C}_{\mathrm{e}}$ values .

\begin{tabular}{|l|c|c|c|c|c|c|}
\hline $\mathrm{Re}_{\mathrm{m}}$ & 4338 & 10149 & 40000 & 70000 & 120000 & 240000 \\
\hline Eqn.(11) & 0.0103 & 0.00791 & 0.0054 & 0.0047 & 0.0041 & 0.0035 \\
\hline $\mathrm{C}_{\mathrm{e}}$ & 0.0103 & 0.00845 & 0.0053 & 0.0046 & 0.0040 & 0.0035 \\
\hline
\end{tabular}

\section{Table 1. Performance of turbulent viscosity for channel flow}

$\mathrm{C}_{\mathrm{e}}$ values are digitized from fig.(8) of ref.(7) and fig.(3) of ref.(8).

B - Flow over a flat plate

Local skin friction coefficients of a flat plate for laminar flow is known as 'Blasius Solution' ;

$$
\mathrm{C}_{\mathrm{f}, \mathrm{x}}=0.664 / \operatorname{Re}_{x}^{1 / 2}=0.664 /\left(\frac{u x}{v}\right)^{1 / 2}
$$

where $\mathrm{u}$ is the free stream velocity, $\mathrm{x}$ streamwise distance from a reference point .

I replace $v$ with $v_{\mathrm{t}}$ given with eqn.(7) and get a formula for turbulent local friction coefficient as follows ;

$$
\begin{aligned}
& C_{f, x}^{\eta}=0.1521415 \operatorname{Re}_{x}^{-1 / 6} \operatorname{Re}_{x}^{-0.103 \operatorname{erf} c\left(\frac{\ln \ln x}{\ln \operatorname{Rexc}}-1\right)} \\
& \ln \operatorname{Re}_{\mathrm{x}, \mathrm{c}}=14.543+1.382 \operatorname{erf}\left(\operatorname{lnRe}_{\mathrm{x}} / 14.543-1\right)
\end{aligned}
$$

I corrected critical local Re number in accord with the experimentally observed value of $2.07 \times 10^{6}$ so I use 14.543 in place of 8.105 . I compare eqn.(13) with experimentally obtained skin frictions in Table (2) . For low values of $\operatorname{Re}_{\mathrm{x}}$ ref.(9) gives numerical values, for higher values of $\mathrm{Re}_{\mathrm{x}}$ ref.(10) gives modified experimental equations so I used the equation of White as corrected in ref.(10);

$$
\mathrm{C}_{\mathrm{f}, \mathrm{x}}=0.4177\left(\ln \left(0.06 \mathrm{Re}_{\mathrm{x}}\right)\right)^{-2}
$$

\begin{tabular}{|c|c|c|c|}
\hline $\operatorname{Re}_{\mathrm{x}}$ & Eqn.(13) & Ref.(7) & Eqn.(14) \\
\hline $3.3 \times 10^{5}$ & 0.00418 & 0.00417 & 0.00417 \\
\hline $7.6 \times 10^{5}$ & 0.00358 & 0.00340 & 0.00363 \\
\hline $10^{6}$ & 0.00336 & 0.00330 & 0.00345 \\
\hline $6.406 \times 10^{6}$ & 0.00252 & - & 0.00253 \\
\hline $3.176 \times 10^{7}$ & 0.00200 & - & 0.00200 \\
\hline $6.061 \times 10^{7}$ & 0.00184 & - & 0.00183 \\
\hline
\end{tabular}

Table 2. Performance of turbulent viscosity for a boundary layer 
C - Convective heat transfer from a flat plate

Laminar exact solution given by Pohlhausen as given in ref.(3) is written below ;

$$
\mathrm{Nu}_{\mathrm{x}}=0.332 \operatorname{Re}_{x}^{1 / 2} \operatorname{Pr}^{1 / 3}
$$

where $\mathrm{Nu}_{\mathrm{x}}=\mathrm{hx} / \mathrm{k}$, local Nusselt number, $\mathrm{Pr}=\mu \mathrm{C}_{\mathrm{p}} / \mathrm{k}$, Prandtl number, $\mathrm{h}$ heat transfer coefficient , $\mathrm{k}$ thermal conductivity, $\mathrm{C}_{\mathrm{p}}$ heat capacity at constant pressure, $\mathrm{x}$ streamwise distance from a reference point .

I replace $\mu$ ( or $v$ ) and $\mathrm{k}$ in eqn.(15) with their turbulent counterparts i.e. with eqn.(7).

$$
v_{\mathrm{t}} / \mathrm{v}=\mathrm{k}_{\mathrm{t}} / \mathrm{k}=0.0525(\mathrm{u} \mathrm{x} / \mathrm{v})^{2 / 3}(\mathrm{u} \mathrm{x} / \mathrm{v})^{-0.206 \text { erfc }(\ln \operatorname{Rex} / \ln \operatorname{Rexc}-1)}
$$

Hence following equation for turbulent heat transfer from a flat plate is obtained.

$$
N u_{x}^{\eta}=0.07607 \operatorname{Pr}^{1 / 3} \operatorname{Re}_{x}^{0.8333} \operatorname{Re}_{x}^{-0.103 \operatorname{erfc}\left(\frac{\ln \operatorname{Rex}}{\ln \operatorname{Rexc}}-1\right)}
$$

$\operatorname{lnRexc}$ is calculated with eqn.(13a) .

Table ( 3 ) compares eqn.(16) with experimental formulas ;

For $10^{5}<\operatorname{Re}_{\mathrm{x}}<10^{7} \quad \mathrm{Nu}_{\mathrm{x}}=0.0292 \operatorname{Pr}^{1 / 3} \operatorname{Re}_{x}^{0.8}$

For $10^{7}<\operatorname{Re}_{\mathrm{x}}<10^{9} \quad \mathrm{Nu}_{\mathrm{x}}=0.185 \operatorname{Pr}^{1 / 3} \operatorname{Re}_{\mathrm{x}}\left(\log _{10} \operatorname{Re}_{\mathrm{x}}\right)^{-2.584}$

which are taken from a standart textbook ${ }^{(11)} . \operatorname{Pr}=0.71$ was used in the calculations .

\begin{tabular}{|c|r|c|c|}
\hline $\mathrm{Re}_{\mathrm{x}}$ & eqn.(16) & eqn.(17) & eqn.(18) \\
\hline $10^{5}$ & 237 & 261 & - \\
\hline $10^{6}$ & 1522 & 1644 & - \\
\hline $10^{7}$ & 10508 & - & 10811 \\
\hline $10^{8}$ & 76983 & - & 76561 \\
\hline $10^{9}$ & 590575 & - & 564714 \\
\hline
\end{tabular}

Table 3. Performance of turbulent diffusivities for heat transfer

It is a well known fact that heat transfer experiments are difficult to perform and may contain a number of errors due to radiation and free convection effects etc. . Yet eqn.(16) compares reasonably well with experiments.

D - Turbulent flow due to a single rotating disc

An analytical exact solution is given by T. Von Karman for laminar flow . The moment coefficient is given below as corrected by Cochran in ref.(12);

$$
\mathrm{C}_{\mathrm{M}}=1.935 / R e_{\varnothing}^{1 / 2}
$$


where $R e_{\emptyset}=\Omega \mathrm{b}^{2} / \mathrm{v}$ is the rotational Reynolds number. $\Omega$ and $\mathrm{b}$ being angular speed and outer radius of disc respectively. Ref.(12) gives an experimental formula for turbulent flow ;

$$
\mathrm{C}_{\mathrm{M}}=0.0655 \operatorname{Re}_{\emptyset}^{-0.186}
$$

Fully turbulent flow appears at a critical $R e_{\emptyset}$ number of $6 \times 10^{5}$

I use the same practise , I employ turbulent viscosity in eqn.(19) in order to obtain turbulent moment coefficient $C_{M}^{\eta}=1.935 /\left(\Omega \mathrm{b}^{2} / v_{\mathrm{t}}\right)^{1 / 2}$ where

$$
\begin{gathered}
v_{\mathrm{t}}=\frac{0.0525}{2 \pi} R e_{\varnothing}^{2 / 3} \operatorname{Re}_{\varnothing}^{-0.206 \operatorname{erf} c\left(\frac{\ln \ln \phi}{\ln R e c}-1\right)} \\
C_{M}^{\eta}=0.17688 \operatorname{Re}_{\varnothing}^{-1 / 6} \operatorname{Re}_{\emptyset}^{-0.103 \operatorname{erfc}\left(\frac{\ln \operatorname{Re} \emptyset}{\ln \operatorname{Rec}}-1\right)}
\end{gathered}
$$

where ;

$$
\ln \operatorname{Rec}=13.305+1.382 \operatorname{erf}\left(\operatorname{lnRe}_{\phi} / 13.305-1\right)
$$

Table (4) compares eqn.(20) with eqn.(21) .

\begin{tabular}{|l|c|c|c|c|}
\hline $\operatorname{Re}_{\phi}$ & $6 \times 10^{5}$ & $2 \times 10^{6}$ & $5 \times 10^{6}$ & $10^{7}$ \\
\hline eqn.(20) & $5.51 \times 10^{-3}$ & $4.41 \times 10^{-3}$ & $3.72 \times 10^{-3}$ & $3.27 \times 10^{-3}$ \\
\hline eqn.(21) & $4.89 \times 10^{-3}$ & $4.04 \times 10^{-3}$ & $3.53 \times 10^{-3}$ & $3.21 \times 10^{-3}$ \\
\hline
\end{tabular}

\section{Table 4. Performance of turbulent viscosity for rotating disc}

E- Rotating cylinder in a quiescent fluid

There is an exact analytical solution ${ }^{(13)}$ and skin friction formula is as follows ;

$$
\mathrm{C}_{\mathrm{f}}=4 / R e_{\omega}
$$

where $R e_{\omega}=\omega \mathrm{a}^{2} / v, \omega$ is the angular velocity, $\mathrm{a}$ is the radius of cylinder. Measurements of skin friction coefficients covering laminar and turbulent flow regions for smooth and rough surfaced cylinders are provided in ref.(14). Some of smooth flow data plotted in fig.(10) of ref.(14) are digitized and is used for comparison with present work.Again I replace $v$ in eqn.(22) with $v_{t}$ as given in eqn.(7) to obtain ;

$$
C_{f}^{\eta}=0.21 \operatorname{Re}_{\omega}^{-1 / 3} \operatorname{Re}_{\omega}^{-0.206 \operatorname{erfc}\left(\frac{\ln R e \omega}{\ln R e c}-1\right)}
$$

I noticed that second multiplier in eqn.(23) was making fit worse. So I removed it and use 
the reminder, i.e. I have taken second multiplier equal to 1 as if $R e_{\omega} \rightarrow \infty$.

$$
C_{f}^{\eta}=0.21 R e_{\omega}^{-1 / 3}
$$

I believe that strict one dimentionality of this flow prevents merging of turbulent eddies, this situation corresponds very high Reynolds numbers for multi-dimentional flows.Following paragraphs on rough flows will shed some ligh on this matter I believe.

Table (6) compares eqn.(24) with experiments.

\begin{tabular}{|c|l|l|l|l|c|l|l|}
\hline$R e_{\omega}$ & 1451 & 6210 & 10119 & 32897 & 83703 & 215844 & 317834 \\
\hline ref.(15) & 0.0179 & 0.0102 & 0.0087 & 0.0063 & 0.0050 & 0.0040 & 0.0038 \\
\hline Eqn.(24) & 0.0185 & 0.0114 & 0.0097 & 0.0066 & 0.0048 & 0.0035 & 0.0031 \\
\hline
\end{tabular}

\section{Table 5. Performance of turbulent viscosity for rotating cylinder}

\section{2- Rough flow}

A - Pipe flow

I used rough flow data from ref.(1) and ref.(2) and obtained the following equations for turbulent rough pipe flow, for details see Supplementary Information Section B .

$$
\begin{aligned}
& \lambda_{\mathrm{k}}=4 C_{f}^{k}=0.4484\left(\frac{D}{k}\right)^{-1 / 3}\left(\frac{D}{k}\right)^{-0.206 \operatorname{erfc}\left(\frac{\ln \left(\frac{D}{k}\right)}{\ln \left(\frac{D}{k c}\right)}-1\right)} \\
& \ln (\mathrm{D} / \mathrm{kc})=4.3714+\operatorname{erf}(\ln (\mathrm{D} / \mathrm{k}) / 4.3714-1)
\end{aligned}
$$

A comparison between eqns.(4) and (25) shows that powers to Re and D/k are the same. This similarity suggest that $\mathrm{Re}$ and $\mathrm{D} / \mathrm{k}$ has similar effects on friction coefficients and imposes two important questions which must be answered. What is the characteristic eddie size $\eta$ for a given Re number ? or can we convert smooth flow Re number into a fully rough regime roughness, D/k, so that we can get the same friction coefficient for this Re and D/k pair ? Second question stems from a more practical problem ; for a given roughness, $\mathrm{D} / \mathrm{k}$, at what Re number roughness effects starts to show up ?

Using eqn.(4) and eqn.(5) in eqn.(2) and putting L=D following equation is obtained ;

$$
\frac{D}{\eta}=0.0525 \operatorname{Re}^{2 / 3} R e^{-0.206 \operatorname{erfc}\left(\frac{\ln R e}{\ln R e c}-1\right)}
$$

Using eqn.(26) and experimental data I have obtained the following relation between $\mathrm{D} / \eta$ and $\mathrm{D} / \mathrm{k}$; 
$\mathrm{D} / \mathrm{k}=0.53933(1+1.236 \operatorname{erf}(\ln \operatorname{Re} / \ln \operatorname{Rec}-1)) \mathrm{D} / \eta=\mathrm{K}(\operatorname{Re}) \mathrm{D} / \eta$

$\mathrm{K}(\mathrm{Re})$ is a correction to eqn.(26) . There may be a number of reasons for this correction.

The difference between roughness length and roughness generated eddies 's length may be one of them .The answer to the second question obtained from experimental values ,eqn.(4) and eqn.(25) is given below ;

$$
\operatorname{Re}=(0.1488+0.103 \operatorname{erfc}(\operatorname{lnD} / \mathrm{k} / \operatorname{lnD} / \mathrm{kc}-1)) D / k^{H\left(\frac{D}{k}\right)}
$$

where $\mathrm{H}(\mathrm{D} / \mathrm{k})=4.854 /(3.236-\operatorname{erfc}(\operatorname{lnD} / \mathrm{k} / \mathrm{lnD} / \mathrm{kc}-1))$

To complete the picture, we have to study the transitionally rough regime : An inspection of Nikuradse' s diagram, fig.(1) shows that when Re number and corresponding D/e, calculated from eqn.(27) reaches D/k of a particular sand roughened pipe, friction factor $\lambda^{\eta},\left(C_{f}^{\eta}\right)$, starts to deviate from eqn.(4), D/e being the effective roughness. First $\lambda$ reaches a minimum where $\mathrm{D} / \mathrm{e} \cong 1.618 \mathrm{D} / \mathrm{k}$. As $\operatorname{Re}$ number is further increased $\lambda$ starts to rise and asymptotically approaches $\lambda_{\mathrm{k}}\left(=4 C_{f}^{k}\right)$ which is given by eqn.(25). A scenerio which may explain the situation is as follows ; Number of roughness created eddies increases as Re number increases and these eddies are fixed in size and they are ,at a certain Re number, are larger in size then the eddies created in the fluid. This is much more pronounced as Re number increases further since inflow created eddies becomes smaller with increasing Re number. These smaller eddies are probably merged by larger eddies of size $\mathrm{D} / \mathrm{k}$ hence eddie size tends to be what is created at the solid-fluid interface and friction factor becomes independent of $\mathrm{Re}$ number or becomes $\lambda_{\mathrm{k}}$. I imitated this scenerio by allowing D/e to increase as $\mathrm{D} / \mathrm{e}=\mathrm{D} / \eta-0.0525 \mathrm{D} / \eta$ till it reaches $1.618 \mathrm{xD} / \mathrm{k}$ which corresponds to $\lambda_{\min }$ and then allowed it to decrease as $\mathrm{D} / \mathrm{e}=1.618 \mathrm{D} / \mathrm{k}-0.0525 \mathrm{D} / \eta$ till it reaches to $\mathrm{D} / \mathrm{k}$ and then $\mathrm{kept}$ it constant at $\mathrm{D} / \mathrm{e}=\mathrm{D} / \mathrm{k}$. Data on the Moody diagram was used for fully rough flow only . Fig.(2) compares experimental friction factors with calculated friction factors inclusive of all three regimes of flow . D/e is taken as D/k for rough flow .For smooth flow D/e is calculated with eqn.(27). The way to obtain D/e is described in the previous paragraph 
for transitionally rough regime. Friction factor $\lambda=4 C_{f}^{k}$ are then calculated with eqn.(25) and eqn.(25a) using D/e in place of D/k . I have not included the nine higher Re number experiments in fig.(2) not only because they are suspected to be somewhat erroneous ${ }^{(15)}$

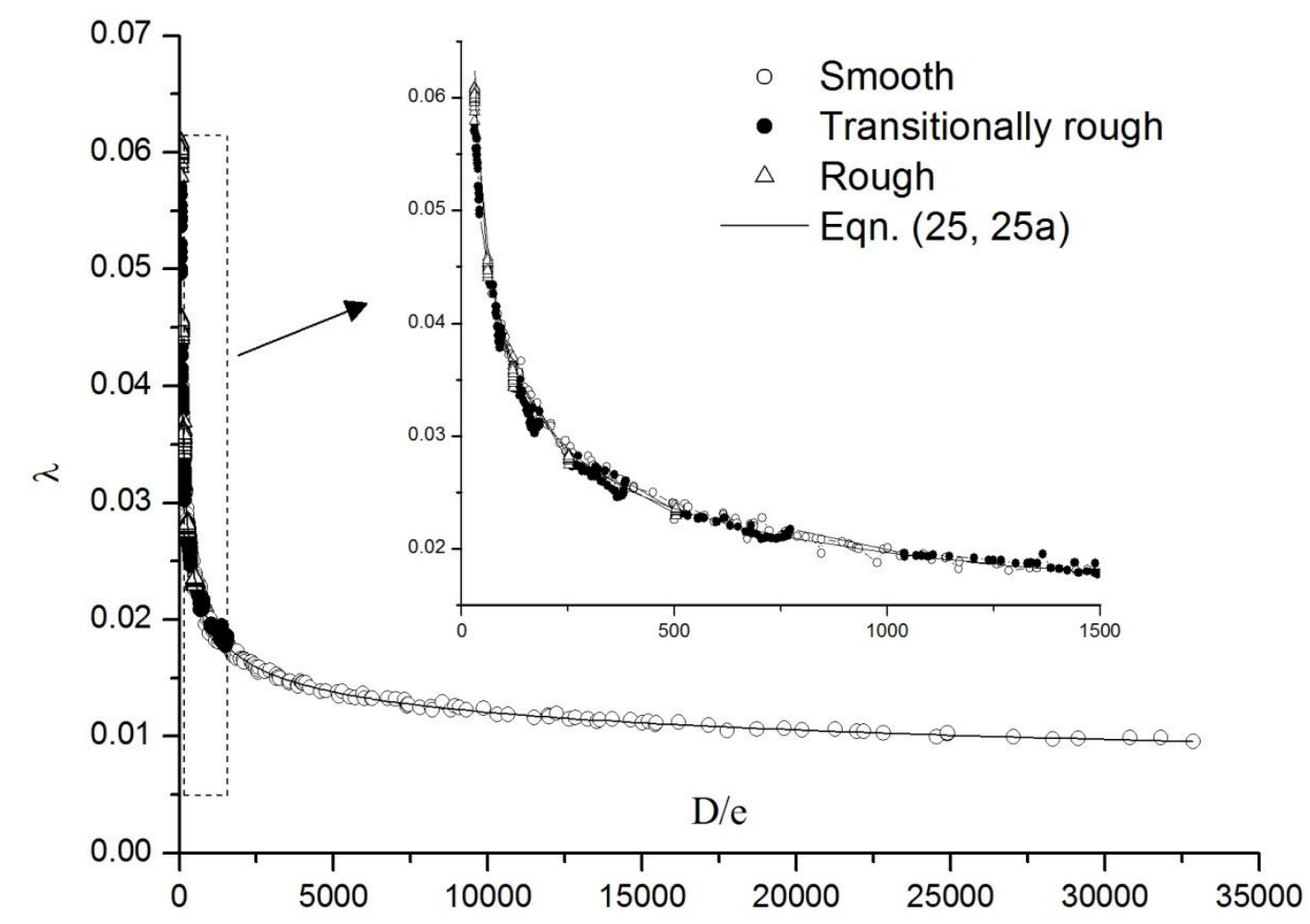

Figure 2. Comparison of general friction factor curve with experiments for pipe flow but more importantly inclusion of these higher D/e (i.e. higher Re ) experiments would make the range of D/e very high hence would cause the main body of experiments squeezed in a narrow band of D/e axis. I rather preferred to zoom in to show different parts of graph precisely. The computer programme and data used in producing Fig.(2) is given at the end of the Supplementary Information as Section C .

B - Rotating rough cylinder

Ref.( 14 ) gives drag coefficients for $\mathrm{k} / \mathrm{a}=0.06,0.03,0.012,0.005$ and 0.002 for rotating rough cylinder . I obtained the following approximate fit from fig.(8) of ref.(14) :

$$
\mathrm{C}_{\mathrm{f}}=0.0525(\mathrm{a} / \mathrm{k})^{-1 / 3}
$$

Table (6) compares eqn.(29) with experiments. It does not have the second multiplier and in 


\begin{tabular}{|c|c|c|c|c|c|}
\hline $\mathrm{k} / \mathrm{a}$ & 0.06 & 0.03 & 0.012 & 0.005 & 0.002 \\
\hline ref.(12) & 0.0196 & 0.0149 & 0.00112 & 0.0091 & 0.0067 \\
\hline eqn.(29) & 0.0206 & 0.0163 & 0.00120 & 0.0090 & 0.0066 \\
\hline
\end{tabular}

Table 6. Performance of eqn.(29)

that respect it is similar to smooth flow rotating cylinder fit. A link between $R e_{\omega}$ and a/k can be obtained using eqn.(24) and eqn.(29) i.e. $0.21 R e_{\omega}^{-1 / 3}=0.0525\left(\frac{a}{k}\right)^{-1 / 3}$ hence ;

$$
\frac{a}{\eta}=R e_{\omega} / 64
$$

Fig.(8) of ref.(14) shows that whenever $\operatorname{Re}_{\omega} / 64=\mathrm{a} / \mathrm{k}(=\mathrm{a} / \eta)$ smooth flow regime ends. There might be a transitionally rough regime but for sufficiently large $\mathrm{Re}_{\omega}$ fully rough regime establishes. For a relative roughness of $\mathrm{k} / \mathrm{a}=0.03$ density of spacing of grains was studied using $90,310,730$ and 2200 grains per square inch . 2200 grains per sq.in. gives saturation beyond which fully rough regime exists. The measurements of skin friction coefficients is plotted against $\operatorname{Re}_{\omega}$ in fig.(10) of ref.(14). It can be seen that friction coefficient is a function of $\operatorname{Re}_{\omega}$, and density of grains . We may define an equivalent roughness as follows ;

$$
\mathrm{k}_{\mathrm{eq}} / \mathrm{a}=\mathrm{S} / \mathrm{S}_{\mathrm{sat}} \cdot \frac{k}{a}+\left(\mathrm{S}_{\mathrm{sat}}-\mathrm{S}\right) / \mathrm{S}_{\mathrm{sat}} \cdot \frac{\eta}{a}
$$

where $\mathrm{S}$ is the number of grains per square inch and sat indicates saturation . Using eqn.(30) in eqn.(31) for internal roughness $\eta /$ a following equation is obtained and this is the equation to be compared with experiments .

$$
\mathrm{k}_{\mathrm{eq}} / \mathrm{a}=\mathrm{S} / \mathrm{S}_{\mathrm{sat}} \cdot \frac{k}{a}+\left(\mathrm{S}_{\mathrm{sat}}-\mathrm{S}\right) / \mathrm{S}_{\mathrm{sat}} \cdot 64 / \operatorname{Re}_{\omega}
$$

For $\mathrm{k} / \mathrm{a}=0.03, \mathrm{~S}=90$ and $\mathrm{Re}_{\omega}=50448$ eqn.(32) provides $\mathrm{k}_{\mathrm{eq}} / \mathrm{a}$ and using eqn.(29) skin friction coefficient is obtained :

$$
\begin{aligned}
& \mathrm{k}_{\mathrm{eq}} / \mathrm{a}=\frac{90}{2200} \cdot 0.03+\frac{2200-90}{2200} \cdot \frac{64}{50448}=2.444 \times 10^{-3} \\
& \mathrm{C}_{\mathrm{f}}=0.0525\left(1 / 2.444 \times 10^{-3}\right)^{-1 / 3}=7.07 \times 10^{-3}
\end{aligned}
$$

experimental value is $7.67 \times 10^{-3}$. Table (7) compares eqn.(32) with experiments.

\begin{tabular}{|c|c|c|c|c|c|l|l|l|l|}
\hline $\mathrm{S}$ & 90 & 90 & 90 & 310 & 310 & 310 & 730 & 730 & 730 \\
\hline $\mathrm{Re}_{\omega}$ & 10308 & 58301 & 243596 & 10175 & 52538 & 176978 & 10178 & 54709 & 179486 \\
\hline ref.(12 & 0.0097 & 0.0066 & 0.006 & 0.012 & 0.010 & 0.0091 & 0.013 & 0.0125 & 0.013 \\
\hline eqn.(31) & 0.0101 & 0.0065 & 0.006 & 0.011 & 0.009 & 0.0087 & 0.013 & 0.0112 & 0.011 \\
\hline
\end{tabular}

Table 7 . Performance of eqn.(32) and eqn.(24) for unsaturated rough flow 
Conclusions : A turbulence scaling factor has been defined and has been used in obtaining a turbulent viscosity and a turbulent heat conductivity which convert a laminar solution to a turbulent solution in obtaining skin friction and heat transfer from a solid surface . Turbulent solutions are in good agreement with experiments .

Present work predicts the lengths of internaly generated turbulent eddies and roughness created turbulent eddies. Using this new knowledge and available experimental works it is shown that largest eddies determine skin friction and heat transfer . If there is mixing of eddies smaller eddies are merged by larger ones and this is the suggested model for roughness effects which dominates at large enough Reynolds numbers. A single effective roughness which determines the friction factor has also been defined. Friction factor depends only on this effective roughness irrespective of flow regimes. Fractal dimention of turbulence is also given which is in accord with measurements for turbulent/non-turbulent interfaces. 

Figures

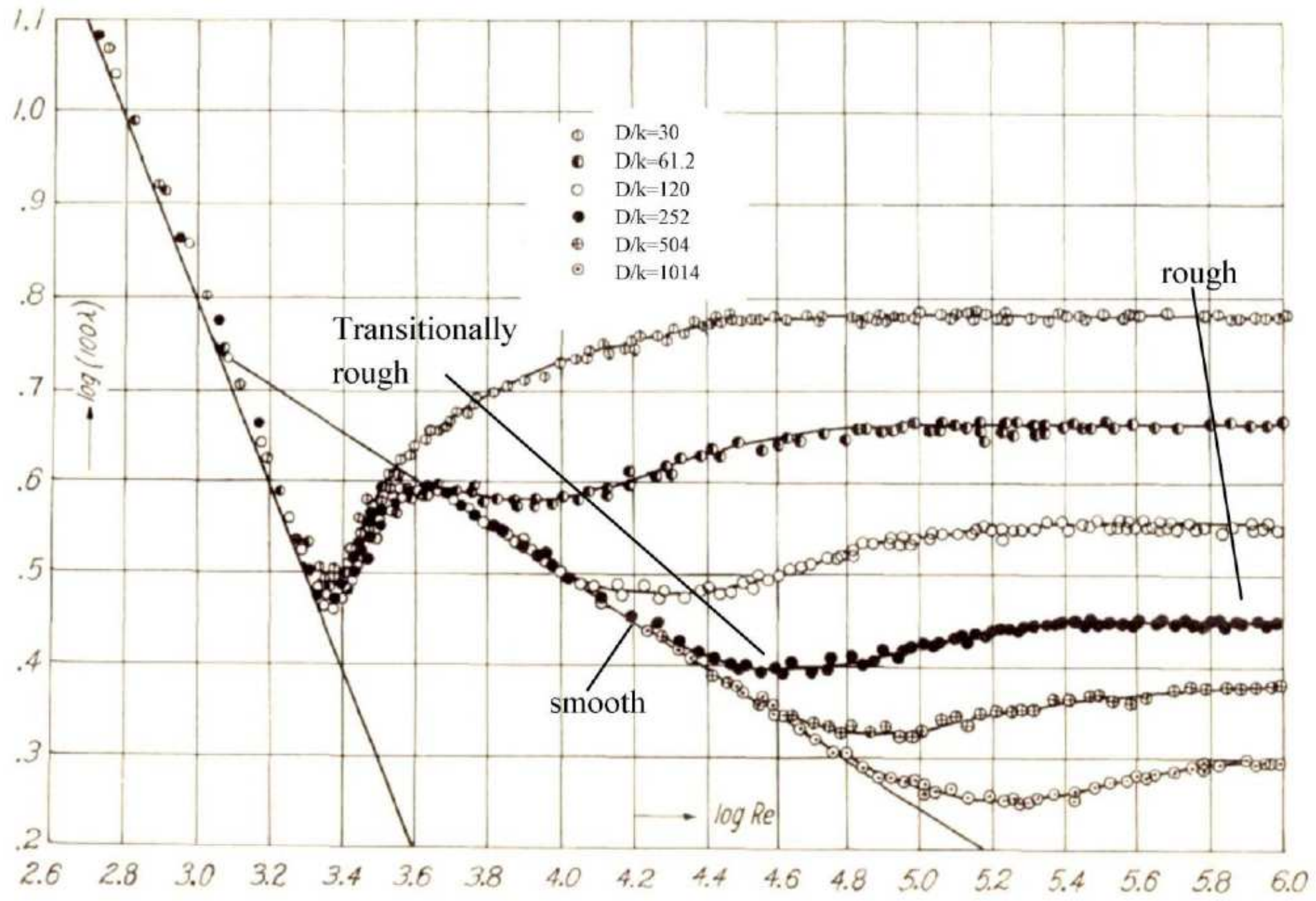

Figure 1

Nikuradse diagram 


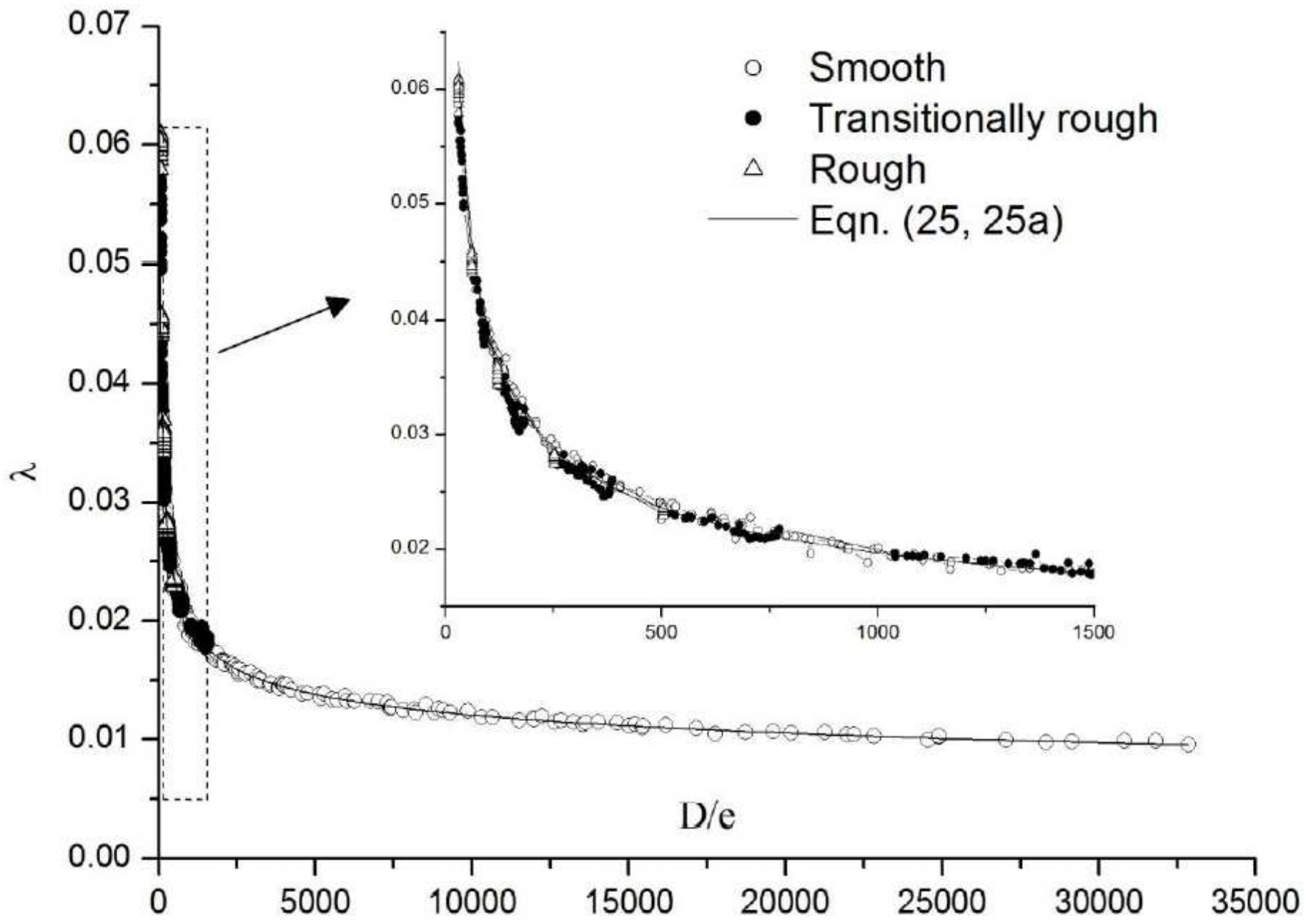

Figure 2

Comparison of general friction factor curve with experiments for pipe flow

\section{Supplementary Files}

This is a list of supplementary files associated with this preprint. Click to download.

- References.pdf

- Supplementarylnformation.pdf

- SIGuide.pdf 